\title{
HUBUNGAN PENDIDIKAN DAN PENGETAHUAN IBU TERHADAP PEMILIHAN KONTRASEPSI SEDERHANA DI POSKESDES GUNUNG IBUL KOTA PRABUMULIH TAHUN 2021
}

\author{
THE RELATIONSHIP OF MOTHER'S EDUCATION AND KNOWLEDGE TOWARDS THE \\ SELECTION OF SIMPLE CONTRACEPTIVE AT POSKESDES GUNUNG IBUL CITY, \\ PRABUMULIH IN 2021
}

\author{
$\underline{\text { Rani Oktarina }}$ \\ Akademi Kebidanan Rangga Husada Prabumulih \\ Email :ranioktarina86@gmail.com
}

\begin{abstract}
ABSTRAK
Metode kontrasepsi sederhana meliputi metode kontrasepsi sederhana tanpa alat yaitu Metode Amenorhoe Laktasi (MAL), Coitus Interuptus, Metode Kalender, Metode Lendir Serviks, Metode Suhu Basal Badan dan Simptotermal yaitu perpaduan antara suhu basal dan ledir serviks. Sedangkan kontrasepsi sederhana dengan alat yaitu kondom, diagfragma, cup serviks dan spermisida. Tujuan penelitian untuk mengetahui hubungan pendidikan dan pengetahuan ibu terhadap pemilihan alat kontrasepsi sederhana di Poskesdes Gunung Ibul Kota Prabumulih Tahun 2021.Penelitian menggunakan Survey Analitik dengan menggunakan pendekatan Cross Sectional.Populasi penelitian adalah seluruh akseptor $k b$ yang berjumlah 85 responden. Jumlah sampel pada penelitian ini adalah 78 responden.Pada analisa univariat diketahui bahwa dari 78 responden dari 85 responden didapatkan bahwa ibu dengan pendidikan tinggi sebanyak 65 responden (76,5\%) dan ibu dengan pendidikan rendah sebanyak 20 responden $(23,5 \%)$ dan ibu berpengetahuan baik sebanyak 57 responden (73,1\%) dan ibu dengan berpengetahuan kurang baik sebanyak 21 responden (26,9\%).Analisa Bivariat menunjukkan pendidikan ibu dalam pemilihan alat kontraasepsi sederhana ( $p$ value 0,002) dan pengetahuan ibu dalam pemilihan alat kontrasepsi sederhana ( $p$ value 0,004).Simpulan dari penelitian ini adalah bahwa ada hubungan pendidikan dan pengetahuan ibu terhadap pemilihan alat kontrasepsi sederhana di Poskesdes Gunung Ibul Kota Prabumulih Tahun 2021.
\end{abstract}

Kata Kunci :Pendidikan, Pengetahuan, Alat Kontrasepsi Sederhana

\begin{abstract}
Simple contraceptive methods consist methods of contraception without tools consist Lactational Amenorrhea Method (MAL), Coitus Interuptus, Calendar Method, Cervical Mucus Method, Basal Body Temperature Method and Symptothermal which is a combination of basal temperature and cervical mucus. While simple contraception with tools, namely condoms, diaphragms, cervical cups and spermicides. The purpose of study was to determine the relationship between education and mother's knowledge of the selection of simple contraceptives at Poskesdes Gunung Ibul, Prabumulih City in 2021. This study used a survey Analytical using Cross Sectional approach. The population of this study were all family planning acceptors with a total of 85 respondents. The number of samples in this study were 78 respondents. In the univariate analysis, it was found that from 78 respondents from 85 respondents it was found that mothers with higher education were 65 respondents (76.5\%) and mothers with low education were 20 respondents (23.5\%) and mothers with good knowledge were 57 respondents $(73,1 \%)$ and mothers with poor knowledge were 21 respondents $(26.9 \%)$. Bivariate analysis showed mother's education in choosing simple contraceptive devices ( $p$ value 0.002) and mother's knowledge in choosing simple contraceptives ( $p$ value 0.004).The conclusion of this study is
\end{abstract}


that there is a relationship between mother's education and knowledge on the selection of simple contraceptives at Poskesdes Gunung Ibul Prabumulih City in 2021.

Keywords: Education, Knowledge, Simple Contraceptives

\section{PENDAHULUAN}

Menurut World Health Organization (WHO) tahun 2019 menyatakan bahwa dua pertiga wanita yang aktif secara seksual yang ingin menunda atau membatasi persalinan berhenti menggunakan kontrasepsi karena takut akan efek samping, masalah kesehatan dan meremehkan kemungkinan terjadinya konsepsi. Hal ini menyebabkan 1 dari 4 kehamilan tidak disengaja. Sementara kehamilan yang tidak diinginkan tidak selalu sama dengan kehamilan yang tidak diinginkan, mereka dapat menyebabkan berbagai resiko kesehatan bagi ibu dan anak, seperti kekurangan gizi, penyakit, pelecehan dan penelantaran, bahkan kematian. Kehamilan yang tidak diinginkan selanjutnya dapat menyebabkan siklus kesuburan yang tinggi, serta potensi pendidikan dan pekerjaan yang lebih rendah dan kemiskinan. Angka kelahiran bayi di dunia menurut WHO yaitu bekisar 13.020 bayi akan lahir pada hari pertama tahun 2020. Bayi dari Indonesia akan menyumbang sekitar 3,32 persen dari total 392.078 bayi $^{1}$.

Cakupan peserta KB aktif di Indonesia pada tahun 2017 mencapai 63,22\% tetapi penggunaan Metode Kontrasepsi Jangka Panjang (MKJP) masih sangat rendah dikarenakan pengetahuan masyarakat masih rendah tentang kelebihan metode MKJP dan keterbatasan jumlah tenaga terlatih serta sarana yang ada, dari keseluruhan jumlah peserta $\mathrm{kb}$ aktif hanya $17,45 \%$ yang menggunakan MKJP dan $1,32 \%$ menggunakan KB tradisional ${ }^{2}$. Data akseptor KB di Provinsi Sumatera Selatan tahun 2018 yaitu KB suntik sebanyak 980.365 akseptor, KB implant sebanyak 405.634 akseptor, KB iud sebanyak
397.866 akseptor dan KB lainnya sebanyak 673.922 akseptor $^{3}$.

Data akseptor KB aktif pasangan usia subur khusus daerah kota Prabumulih pada tahun 2019 mencapai target 50 akseptor dalam satu pelayanan KB pada tiap puskesmas antara lain 5 akseptor IUD dan 5 akseptor Implant, sisanya kb alamiah dan kontrasepsi sederhana ${ }^{4}$. Data yang diperoleh poskesdes gunung ibul kota prabumulih terdapat jumlah akseptor $\mathrm{kb}$ pada tahun 2021 sebanyak 242 akseptor diantaranya akseptor kb suntik, pil, IUD, implant dan kondom ${ }^{5}$.

Metode kontrasepsi sederhana terdiri dari 2 yaitu metode kontrasepsi sederhana tanpa alat dan metode kontrasepsi sederhana dengan alat. Metode Amenorhoe Laktasi (MAL), Coitus Interuptus, Metode Kalender, Metode Lendir Serviks, Metode Suhu Basal Badan dan Simptotermal yaitu perpaduan antara suhu basal dan ledir serviks. Sedangkan kontrasepsi sederhana dengan alat yaitu kondom, diagfragma, cup serviks dan spermisida ${ }^{6}$. Pengetahuan dan pendidikan pasangan usia subur sangat menentukan dalam pemilihan kontrasepsi. Hal ini dibuktikan pada pengetahuan yang baik dapat mengoptimalkan mendapatkan pengetahuan yang luas dalam memahami serta mengerti manfaat, kelebihan, kekurangan, jenis alat kontrasepsi.

Pendidikan seseorang yang tinggi akan lebih mudah memahami tentang suatu informasi dan sebaliknya dengan pendidikan rendh sangat sulit mentyerjemahkan tentang informasi yang didapatkan. Maka dari itu pendidikan dan pengetetahuan sangat menentukan seseorang dalam memutuskan kontrasepsi 
CENDEKIA MEDIKA

P-ISSN: 2503-1392

E-ISSN: 2620-5424

apa yang akan digunakan ${ }^{7}$. Pengetahuan atau ranah kognitif merupakan domain yang sangat penting dalam membentuk tidakan seseorang (Overt Behaviour). Apabila seseorang menerima perilaku baru atau adopsi perilaku berdasarkan pengetahuan, kesadaran dan sikap yang positif, maka perilaku akan berlangsung lama. Sebaliknya apabila perilaku itu tidak didasari oleh pengetahuan dan kesadaran maka tidak akan berlangsung lama ${ }^{8}$. Menurut asumsi peneliti pengetahuan merupakan salah satu faktor yang berhubungan dengan penggunaan metode kontrsasepsi sederhana, hal ini dikarenakan semakin baik pengetahuan ibu maka akan semakin baik pula wawasan yang didapatkan oleh ibu. Hasil penelitian juga menunjukkan bahwa ibu yang memiliki pengetahuan baik dan cukup juga masih ada yang tidak menggunakan kontrasepsi efektif terpilih.Beberapa alasan ini yang membuat para ibu dengn pengetahuan baik dan cukup masih tidak mau untuk menggunakan kontrasepsi efektif terpilih ${ }^{9}$.

Jumlah pasangan usia subur dan peserta $\mathrm{Kb}$ Aktif menurut SIMATA (Sistem Informasi Data Satu Sumsel) pada tahun 2019 terdapat jumlah pasangan usia subur sebanyak 42.275 pasangan Puskesmas Aek Godang Padang Lawas Utara secara statistik dengan menggunakan uji chi square diperoleh hasil $p$ value $=\mathrm{p}<0,05$ dengan demikian $\mathrm{H} 0$ ditolak dan $\mathrm{Ha}$ diterima yang artinya ada hubungan pendidikan ibu terhadap pemilihan kontrasepsi efektif dengan nilai $\mathrm{p}$ value $=$ 0,004. Secara statistik dengan menggunakan uji chi square diperoleh hasil $p$ value $=\mathrm{p}<0,05$ dengan demikian $\mathrm{H} 0$ ditolak dan Ha diterima yang artinya ada hubungan pengetahuan ibu terhadap pemilihan kontrasepsi efektif dengan nilai $\mathrm{p}$ value $=0,033^{7}$. Data peserta $\mathrm{kb}$ sederhana di Poskesdes Gunung Ibul pada tahun 2020 terdapat peserta alat kontrasepsi kondom $11 \%$, kalender $0,3 \%$, suhu basal
Volume 6 Nomor 2, September 2021

$0,1 \%$, amenore laktasi $2 \%$, pil $8 \%$, MOW dan MOP 7\%, IUD 15\%, Suntik 55\% dan sisanya alat kontrasepsi lainnya ${ }^{5}$.

Berdasarkan latar belakang di atas penulis termotivasi untuk melakukan penelitian dengan judul Hubungan pendidikan dan pengetahuan ibu terhadap pemilihan kontrasepsi metode sederhana di Poskesdes Gunung Ibul Kota Prabumulih Tahun 2021.

\section{METODE}

Penelitian ini menggunakan metode kuantitatif dengan pendekatan survey analitik yaitu survei atau penelitian yang mencoba menggali bagaimana dan ,mengapa fenomena kesehatan itu terjadi, dengan pendekatan Cross Sectional yaitu studi epidemiologi yang mempelajari prevalensi, distribusi maupun hubungan penyakit. Penelitian ini difokuskan pada hubungan pendidikan dan pengetahuan ibu terhadap pemilihan kontrasepsi metode sederhana di Poskesdes Gunung Ibul Kota Prabumulih Tahun $2021^{9}$.

Populasi adalah keseluruhan objek penelitian atau objek yang diteliti ${ }^{7}$. Seluruh akseptor KB yang berjumlah 78 Responden di Poskesdes Gunung Ibul Kota Prabumulih yang didapatkan melalui kunjungan rumah. Sampel penelitian ini merupakan sampel kualitatif dengan metode sampel penelitian yang digunakan Accidental Sampling (teknik pengambilan yang diambil dari Responden yang ditemukan) yang berjumlah 78 responden ${ }^{9}$.Penelitian ini dilaksanakan di Poskesdes Gunung Ibul Kota Prabumulih Tahun 2021.

Waktu penelitian ini dilaksanakan pada bulan April- Mei tahun 2021.Penelitian ini menggunakan data primer dan sekunder yaitu data diperoleh dari hasil lembar kuisioner akseptor yang menggunakan KB di Poskesdes Gunung Ibul Kota Prabumulih Tahun 2021 dan data yang 
CENDEKIA MEDIKA

P-ISSN: 2503-1392

E-ISSN: 2620-5424

diperoleh dri catatan rekam medis. Data primer adalah data yang didapat dari responden penelitian. Dalam penelitian ini data primer diperoleh dari data Rekam Medik Poskesdes Gunung Ibul Kota Prabumulih, dan penelusuran buku sumber

\section{HASIL}

\section{Analisa Univariat}

Tabel 1.

Distribusi Frekuensi Responden berdasarkan Pendidikan Ibu di Poskesdes Gunung Ibul Kota Prabumulih Tahun 2021

\begin{tabular}{lll}
\hline Pendidikan Ibu & Frekuensi & \% \\
\hline Tinggi & 56 & 76,5 \\
Rendah & 22 & 23,5 \\
\hline Jumlah & $\mathbf{7 8}$ & $\mathbf{1 0 0}$ \\
\hline
\end{tabular}

Dari tabel di atas diketahui bahwa dari 78 responden didapatkan bahwa ibu dengan $(76,5 \%)$ dan ibu dengan pendidikan rendah pendidikan tinggi sebanyak 56 responden

maupun internet mengenai kontrasepsi sederhana.Instrumen yang digunakan adalah kuisioner sebagai panduan mengambil data di Poskesdes Gunung Ibul Kota Prabumulih Tahun 2021.

Tabel 2.

Distribusi Frekuensi Responden berdasarkan Pengetahuan Ibu di Poskesdes Gunung Ibul Kota Prabumulih Tahun 2021

\begin{tabular}{lll}
\hline Pengetahuan Ibu & Frekuensi & \% \\
\hline Baik & 57 & 73,1 \\
Kurang Baik & 21 & 26,9 \\
\hline Jumlah & $\mathbf{7 8}$ & $\mathbf{1 0 0}$ \\
\hline
\end{tabular}

Dari tabel di atas diketahui bahwa dari 78 responden didapatkan bahwa ibu dengan berpengetahuan baik sebanyak 57

responden $(73,1 \%)$ dan ibu dengan berpengetahuan kurang baik sebanyak 21 responden $(26,9 \%)$.

Tabel 3.

Hubungan antara Pendidikan Ibu dalam Pemilihan Kontrasepsi Sederhana di Poskesdes Gunung Ibul Kota Prabumulih Tahun 2021

\begin{tabular}{|c|c|c|c|c|c|c|c|}
\hline \multirow{3}{*}{$\begin{array}{c}\text { Pendidikan } \\
\text { Ibu }\end{array}$} & \multicolumn{4}{|c|}{$\begin{array}{l}\text { Penilihan } \\
\text { Kontrasepsi } \\
\text { Sederbana. }\end{array}$} & \multicolumn{2}{|c|}{ Junalah } & \multirow{3}{*}{$\begin{array}{c}\text { Tingkat } \\
\text { Kemaknaan }\end{array}$} \\
\hline & \multicolumn{2}{|c|}{$\mathbf{Y a}$} & \multicolumn{2}{|c|}{ Tidak } & \multirow{2}{*}{$\mathbf{N}$} & \multirow{2}{*}{$\%$} & \\
\hline & $\mathbf{n}$ & $\%$ & $\mathbf{n}$ & $\%$ & & & \\
\hline Tingei & 32 & 41,0 & 24 & 30,8 & 56 & 71,8 & \multirow{3}{*}{$\begin{array}{c}0,002 \\
\text { Bermakna }\end{array}$} \\
\hline Rendab & 4 & 5,1 & 18 & 23,1 & 22 & 28,2 & \\
\hline Jumalah & 36 & 46,2 & 42 & 53,8 & 78 & 100 & \\
\hline
\end{tabular}


CENDEKIA MEDIKA

P-ISSN: 2503-1392

E-ISSN: 2620-5424

Dari 56 responden dengan pendidikan tinggi terdapat $32(71,8 \%)$ responden yang memilih kontrasepsi sederhana dan 24 $(30,8 \%)$ responden yang tidak memilih kontrasepsi sederhana. Dari 22 responden dengan pendidikan rendah terdapat 4 $(5,1 \%)$ responden yang memilih kontrasepsi sederhana dan $18 \quad(23,1 \%)$ responden yang tidak memilih kontrasepsi sederhana. Berdasarkan hasil analisa bivariat dengan uji statistik mengunakan Chi-Square didapatkan hasil $p$ value $=$ $0,002$ ( $p \leq 0,05)$ berarti hipotesis menyatakan bahwa ada hubungan yang bermakna antara Pendidikan Ibu dalam Pemilihan Kontrasepsi Sederhana terbukti.

Tabel 4.

Hubungan antara Pengetahuan Ibu dalam Pemilihan Kontrasepsi Sederhana di Poskesdes Gunung Ibul Kota Prabumulih Tahun 2021

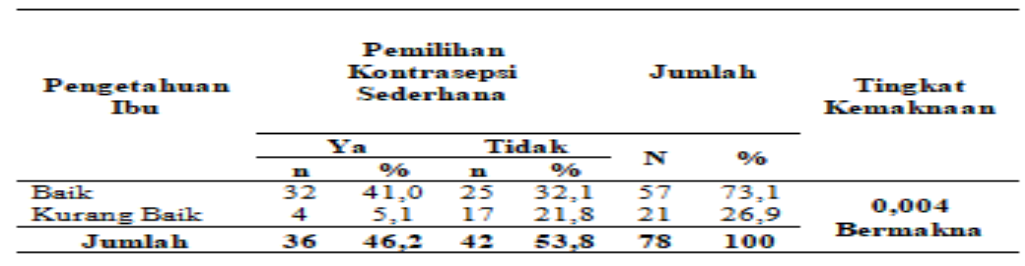

Dari 57 responden dengan pengetahuan baik terdapat $32(41,0 \%)$ responden yang memilih kontrasepsi sederhana dan 25 $(32,1 \%)$ responden yang tidak memilih kontrasepsi sederhana. Dari 21 responden dengan pengetahuan kurang baik terdapat $4(5,1 \%)$ responden yang memilih kontrasepsi sederhana dan $17(21,8 \%)$ responden yang tidak memilih kontrasepsi sederhana. Berdasarkan hasil analisa bivariat dengan uji statistik mengunakan Chi-Square didapatkan hasil $p$ value $=$ $0,004$ ( $p \leq 0,05)$ berarti hipotesis menyatakan bahwa ada hubungan yang bermakna antara Pengetahuan Ibu dalam Pemilihan Kontrasepsi Sederhana terbukti.

\section{PEMBAHASAN}

Hubungan antara Pendidikan Ibu dalam Pemilihan Kontrasepsi Sederhana di Poskesdes Gunung Ibul Kota Prabumulih Tahun 2021

Pada penelitian ini variabel Pendidikan Ibu dibedakan menjadi dua bagian yaitu Tinggi (Bila ibu berpendidikan $\geq$ SMU) dan Rendah (Bila ibu berpendidikan < SMU). Hasil analisa univariat didapatkan bahwa dari 85 responden didapatkan bahwa ibu dengan pendidikan tinggi sebanyak 65 responden $(76,5 \%)$ dan ibu dengan pendidikan rendah sebanyak 20 responden $(23,5 \%)$. Hasil analisa bivariat didapatkan dari 56 responden dengan pendidikan tinggi terdapat $32(71,8 \%)$ responden yang memilih kontrasepsi sederhana dan $24(30,8 \%)$ responden yang tidak memilih kontrasepsi sederhana. Dari 22 responden dengan pendidikan rendah terdapat $4(5,1 \%)$ responden yang memilih kontrasepsi sederhana dan $18 \quad(23,1 \%)$ responden yang tidak memilih kontrasepsi sederhana. Berdasarkan hasil analisa bivariat dengan uji statistik mengunakan Chi-Square didapatkan hasil $p$ value $=$ $0,002$ ( $p \leq 0,05)$ berarti hipotesis menyatakan bahwa ada hubungan yang bermakna antara Pendidikan Ibu dalam Pemilihan Kontrasepsi Sederhana terbukti. Pendidikan mempengaruhi seseorang dalam menggunakan alat kontrasepsi yang mudah digunakan bagi dirinya dan pendidikan merupakan upaya berperilaku dengan cara memberikan kesadaran pada suatu kelompok sehingga membuat ajakan tertentu dalam penggunaan kontrasepsi ${ }^{7}$. 
CENDEKIA MEDIKA

P-ISSN: 2503-1392

E-ISSN: 2620-5424

Pengaruh pendidikan ibu dalam pemilihan alat kontrasepsi berdasarkan teori bahwa pendidikan formal sangat besar pengaruhnya terhadap pengetahuan seseorang, bila ibu berpendidikan tinggi maka semakin tinggi pula ilmu pengetahuan yang didapatkan sebaliknya jika seseorang memiliki pendidikan rendah akan memiliki pengetahuan yang rendah pula dan akan sulit untuk memahami sesuatu hal. Maka dai itu dapat disimpulkan bahwa ibu yang berpendidikan tinggi akan memilih kontrasepsi yang aman bagi dirinya ${ }^{6}$. Hal ini sejalan dengan penelitian yang dilakukan oleh Elfi Suryani Ritonga pada tahun 2018 di Puskesmas Aek Godang Padang Lawas Utara secara statistik dengan menggunakan uji chi square diperoleh hasil $p$ value $=\mathrm{p}<0,05$ dengan demikian $\mathrm{HO}$ ditolak dan Ha diterima yang artinya ada hubungan pendidikan ibu terhadap pemilihan kontrasepsi efektif dengan nilai $\mathrm{p}$ value $=0,004^{9}$.

Hubungan antara Pengetahuan Ibu dalam Pemilihan Kontrasepsi Sederhana di Poskesdes Gunung Ibul Kota Prabumulih Tahun 2021

Pada penelitian ini variabel Pengetahuan Ibu dibedakan menjadi dua bagian yaitu Baik (Bila ibu mampu menjawab pertanyaan $\geq 70 \%$ dengan benar) dan Kurang Baik (Bila ibu mampu menjawab pertanyaan < $70 \%$ dengan benar). Hasil analisa univariat didapatkan dari 78 responden didapatkan bahwa ibu dengan berpengetahuan baik sebanyak 57 responden $(73,1 \%)$ dan ibu dengan berpengetahuan kurang baik sebanyak 21 responden $(26,9 \%)$.Hasil analisa bivariat didapatkan 57 responden dengan pengetahuan baik terdapat $32 \quad(41,0 \%)$ responden yang memilih kontrasepsi sederhana dan $25(32,1 \%)$ responden yang tidak memilih kontrasepsi sederhana. Dari 21 responden dengan pengetahuan kurang baik terdapat $4(5,1 \%)$ responden yang memilih kontrasepsi sederhana dan 17
$(21,8 \%)$ responden yang tidak memilih kontrasepsi sederhana.

Berdasarkan hasil analisa bivariat dengan uji statistik mengunakan Chi-Square didapatkan hasil $p$ value $=0,004(p \leq$ $0,05)$ berarti hipotesis menyatakan bahwa ada hubungan yang bermakna antara Pengetahuan Ibu dalam Pemilihan Kontrasepsi Sederhana terbukti. Pengetahuan seorang ibu akan berpengaruh dalam mendapatkan informasi kontrasepsi apa yang banyak diminati oleh orang lain. Sehingga ibu berpengetahuan baik akan lebih memilih kontrasepsi yang paling banyak digunakan oleh lingkungannya. Ibu berpengetahuan tinggi / baik akan membuat ibu mudah memahami informasi yang didapatkan tentang kontrasepsi, sehingga ibu dapat memilih kontrasepsi apa yang terbaik yang dapat digunakan. Sebaliknya pengetahuan ibu yang kurang baik akan menyulitkan ibu untuk memilih kontrasepsi yang akan digunakan $^{7}$.

Hal ini sejalan dengan penelitian yang dilakukan oleh Elfi Suryani Ritonga pada tahun 2018 di Puskesmas Aek Godang Padang Lawas Utara secara statistik dengan menggunakan uji chi square diperoleh hasil $p$ value $=\mathrm{p}<0,05$ dengan demikian $\mathrm{HO}$ ditolak dan Ha diterima yang artinya ada hubungan pengetahuan ibu terhadap pemilihan kontrasepsi efektif dengan nilai $\mathrm{p}$ value $=0,033^{7}$.

\section{KESIMPULAN}

Dari hasil penelitian yang dilakukan di Poskesdes Gunung Ibul Kota Prabumulih dengan jumlah responden 78 orang dapat disimpulkan bahwa ada hubungan yang bermakna antara Pendidikan Ibu dalam Pemilihan Kontrasepi Sederhana di Poskesdes Gunung Ibul Prabumulih Tahun 2021 dimana $p$ value $=(0,002) \leq 0,05$. Ada hubungan yang bermakna antara Pengetahuan Ibu dalam Pemilihan Kontrasepi Sederhana di Poskesdes 
CENDEKIA MEDIKA

P-ISSN: 2503-1392

E-ISSN: 2620-5424

Gunung Ibul Prabumulih Tahun 2021, dimana $p$ value $=(0,004) \leq 0,05$.

\section{SARAN}

Berdasarkan simpulan di atas maka penulis menyarankan dapat menambah wawasan dan pengetahuan dalam mengaplikasikan ilmu pengetahuan yang telah diterima selama kuliah, kepada tenaga kesehatan untuk memotivasi ibu bersalin agar menggunakan alat kontrasepsi yang aman, bagi Poskesdes gunung ibul kota prabumulihdapat memberikan informasi tentang pentingnya penggunaan kontrasepsi dan memilih kontrasepsi yang akan digunakan oleh masyarakat di Poskesdes Gunung Ibul Kota Prabumulih Tahun 2021 serta bagi Institusi Pendidikan disarankan bagi pendidikan agar lebih memperbanyak referensi teori tentang Pemilihan Kontrasepsi. Sehingga peneliti selanjutnya dapat melakukan penelitian dengan kasus variabel berbeda tetapi dengan materi yang lebih lengkap dan metode penelitian yang lebih baik.

\section{DAFTAR PUSTAKA}

1. WHO.2019.http://www/google/co.ang ka-wanita-usia-reproduktif diakses tanggal 26 Maret 2021.
Volume 6 Nomor 2, September 2021

2. Kemenkes

$\mathrm{RI}$, 2018

.htttp:/www.google.co.id.Data-KB-

Aktif-tahun-2018-di-Indoenesia

diakses tanggal 28 April 2021.

3. Dinas Kesehatan Provinsi Sumatera Selatan, 2018 htttp:/www.google.co.id.Data-KBAktif-tahun-2018-di-sumaterasselatan diakses tanggal 28 April 2021.

4. Eti Agustina, 2019. htttp:/www.google.co.id.Data-KBAktif-tahun-2019-kota prabumulih diakses tanggal 28 April 2021.

5. Rekam Medik, 2021.Data Poskesdes Gunung Ibul. 2021.

6. Handayani, 2016.Kontrasepsi.EGC: Jakarta.

7. Elfi Suryani Ritonga (2018) http://google/co/id.hubunganpendidikan-dan-pengetahuan-ibutentang-kontrasepsi-terpilih-efektif-diPuskesmas Aek Godang Padang Lawas Utara di akses tanggal 21 April 2021.

8. BKKBN Sumatera Selatan, 2020.htttp:/www.google.co.id.DataKB-Aktif-tahun-2020 diakses tanggal 28 April 2021.

9. Notoadmodjo. 2014. Metodelogi Penelitian Kesehatan. Jakarta:Renieka Cipta. 